\title{
Estimation of salt intake by 24-hour urinary sodium excretion: a cross-sectional study in Yantai, China
}

Jianwei $\mathrm{Xu}^{1,5}$, Maobo Wang ${ }^{2 *}$, Yuanyin Chen²${ }^{2}$ Baojie Zhen ${ }^{3}$, Junrong Li ${ }^{4}$, Wenbo Luan ${ }^{3}$, Fujiang Ning ${ }^{4}$, Haiyun Liư ${ }^{2}$, Jixiang $\mathrm{Ma}^{5}$ and Guansheng $\mathrm{Ma}^{1}$

\begin{abstract}
Background: High levels of dietary sodium are associated with raised blood pressure and adverse cardiovascular health. To determine baseline salt intake, we investigated the average dietary salt intake from 24-hour urinary sodium excretion with a small sample of Yantai adults in the Shandong province of China.

Methods: One hundred ninety one adults aged 18-69 years were randomly selected from the Yantai adult population. Blood pressure, anthropometric indices and sodium excretion in a 24-hour urine collection were measured. Consumption of condiments was derived from 3-day weighted records. Completeness of urine collections was verified using creatinine excretion in relation to weight.

Results: The mean Na and K outputs over 24 hours were $201.5 \pm 77.7 \mathrm{mmol} /$ day and $46.8 \pm 23.2 \mathrm{mmol} /$ day, respectively (corresponding to $11.8 \mathrm{~g} \mathrm{NaCl}$ and $1.8 \mathrm{~g} \mathrm{~K}$ ). Overall, $92.1 \%$ of the subjects ( $96.9 \%$ of men and $87.1 \%$ of women) had intakes of over $6 \mathrm{~g}$ salt $(\mathrm{NaCl}) / \mathrm{d}$. The main sources of salt intake from weighed condiments records were from home cooking salt (74.7\%) followed by soy sauce (15.0\%). Salt intake from condiments and salt excretion were weakly correlated( $(r=0.20, p=0.005)$. A positive linear correlation between salt intake was associated with systolic blood pressure in all adjusted and unadjusted model $(r=0.16, p=0.01)$. Each $100 \mathrm{mmol} /$ day increase in sodium intake was associated with a $4.0 \mathrm{mmHg}$ increase in systolic blood pressure.
\end{abstract}

Conclusion: Dietary salt intake in Yantai adults was high. Reducing the intake of table salt and soy sauce used in cooking will be an important strategy to reduce sodium intake among Yantai adults.

Keywords: Urinary sodium, Salt intake, Urine

\section{Background}

High salt intake is associated with high blood pressure, which, in turn, increases the risk of stroke and cardiac vascular disease [1-4]. Evidence suggests that modest reductions in dietary sodium could substantially reduce cardiovascular events and medical costs, and should be a public health priority [5]. Internationally, calls have been made for dietary sodium reduction to be a major intervention for the prevention and control of non-communicable diseases [6]. In China, hypertension is a major contributor to cardiovascular disease, which accounts for $40 \%$ of the deaths [7] and $23 \%$ of the health care costs [8]. The China

\footnotetext{
* Correspondence: ytwmb@sina.com

${ }^{2}$ Yantai Center for Disease Control and Prevention, 264003 Yantai, China Full list of author information is available at the end of the article
}

National Nutrition and Health Survey indicated that approximately $80 \%$ of Chinese adults exceeded a salt intake of $6 \mathrm{~g} /$ day in 2002, the recommendation proposal by the Chinese Nutrition Society [9].

There are several methods for measuring salt intake. These include dietary recall or records from 24 to 96 hours, food frequency questionnaire methods and 24hour urine collection. Accurate estimation of salt intake is difficult because the amount of salt added during cooking (even in restaurants) and at the table is usually not known. Further, it is difficult to determine the amount of salt remaining on a serving plate and to determine the salt content in food and drinking water [10]. Generally, 24-hour urine collection is considered to be the most reliable method to evaluate salt intake [10-14].

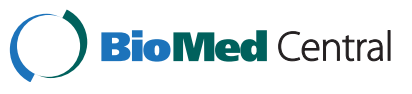


Dietary survey methods tend to underestimate sodium intake [15], while 24-hour urinary sodium excretion is considered the 'gold standard' method [16]. However, the 24-hour urinary excretion method does not account for electrolyte loss other than via the kidneys, and therefore will tend to slightly underestimate true sodium intake [14].

In 2011, the China Ministry of Health (MOH) selected Shandong Province as a national pilot area for sodium reduction and the Shandong and $\mathrm{MOH}$ Action on Salt reduction and Hypertension (SMASH, 2011-2015) Program was launched to lower sodium intake and to prevent and control hypertension. The SMASH Program is the first provincial-wide, government-led salt reduction program in China; it has adopted a multi-sector collaboration approach and has set its goal to reduce the daily salt intake to less than 10 grams by 2015. In 2011, a cross-sectional baseline survey for the SMASH Program was conducted in the general population aged 18 to 69 years. Yantai in the Shandong Province was selected as a pilot site of the SMASH Program for implementing comprehensive multi-sector strategies to decrease salt intake.The aim of this study is to determine the baseline salt intake among the Yantai adult population. These results will provide information to help develop and implement interventions and to enable evaluation of the effect of the ongoing salt reduction program.

\section{Methods}

\section{Subjects}

The baseline survey was conducted in July 2011. According to the multi-stage cluster sampling of the SMASH program, two counties were selected from 16 counties of Yantai. Using a proportional probability sampling method, three townships and two streets were selected and three villages/neighborhoods were selected from each sampled township/street. In each selected village/neighborhood, 100 subjects were selected by random sampling. A total of 1500 subjects aged 18-69 years were selected. Subjects were invited to an assessment that included administration of a standardized questionnaire, physical examination, and laboratory testing. The study protocol was approved by the Ethical Review Committee of the Chinese Center for Disease Control and Prevention, and participants provided written informed consent.

In addition, we also selected a small subsample from the above sample for a 24-hour urine survey. We randomly selected 5 villages/neighborhoods from 15 sampled townships/streets, and among the selected 100 subjects in selected villages/neighborhoods 42 subjects in each selected village/neighborhood were randomly selected and investigated using 3-day dietary recall assessments and 24-hour urine collections. A total of 207 subjects finished both 3-day dietary recall assessments and the 24-hour urine collections. Sixteen urine collections were excluded because of insufficient recovery. A total of 191 subjects involved in the study were selected for this sub-sample.

\section{Physical measurement}

Physical measurements including height, weight, waist circumference, and blood pressure were conducted following standardized methods. Blood pressure (BP) was measured three times by electronic sphygmomanometer (HEM-7071, Omron Corporation, Japan) and the average of the three measures was calculated as used for analyses. Participants were considered hypertensive if the average systolic BP was $\geq 140 \mathrm{mmHg}$ or diastolic BP was $\geq 90 \mathrm{mmHg}$, or they had a prior diagnosis of hypertension and/or were receiving an anti-hypertensive drug.

\section{Assessment of salt intake}

For three consecutive days (including Thursday, Friday, and Saturday) dietary intake was recorded to assess sources of sodium from condiments (including salt, soy sauce, jam, monosodium and Vinegar). A trained health worker went to the selected individual's house in the evening, after the family had finished dinner. The health worker recorded the cooking condiments used, purchased and discarded by weight. We measured consumption by weight at the start and end of the assessment period. The sodium and potassium contents in condiments were calculated using reference values from the China Food Composition Table [17].

\section{4-hour urine collection and measurements}

A single timed 24-hour urine collection was obtained for estimation of electrolyte excretion. Participants were given written and verbal instructions for the 24-hour collection. The first urine of the day was discarded and all urine over the following 24 hours was collected in standard containers that were provided. Total volume of the collection was measured. Urine aliquots were stored at $-20^{\circ} \mathrm{C}$ before being transported frozen to the certified laboratory (ADICON Clinical Laboratory Inc., Jinan, China). In accordance with the standard procedure, urinary sodium and potassium were measured using ion selecting electrode method by Olympus AU 680 autoanalyser (coefficient of variation was $1.5 \%$ for sodium and $2.5 \%$ for potassium). Creatinine was measured using the picric acid method by Olympus AU640 Analyzer (coefficient of variation was $3.0 \%$ ).

The 24-hour urine collections were assessed for completeness using creatinine excretion in relation to weight (i.e. the creatinine coefficient $=$ creatinine $[\mathrm{mg} /$ day $] /$ body weight $[\mathrm{kg}]$ ). Creatinine coefficients of 14.4 to 33.6 in men and 10.8 to 25.2 in women were classified as 
Table 1 Characteristics of the study population by sex

\begin{tabular}{|c|c|c|c|c|c|}
\hline & Men (n 98) & Women (n 93) & Total (n 191) & Statistical value & $P$ value \\
\hline Age (years) & $42.6 \pm 13.2$ & $41.5 \pm 13.7$ & $42.3 \pm 13.5$ & 0.53 & 0.600 \\
\hline Height (cm) & $171.5 \pm 6.4$ & $158.6 \pm 6.5$ & $165.1 \pm 9.1$ & 13.93 & $<0.0001$ \\
\hline Weight (kg) & $73.8 \pm 12.7$ & $62.5 \pm 11.8$ & $68.4 \pm 13.4$ & 6.38 & $<0.0001$ \\
\hline BMI $\left(\mathrm{kg} / \mathrm{m}^{2}\right)$ & $25.1 \pm 4.1$ & $24.9 \pm 4.5$ & $25.0 \pm 4.3$ & 0.33 & 0.743 \\
\hline Waist circumference $(\mathrm{cm})$ & $86.7 \pm 11.5$ & $80.1 \pm 11.3$ & $83.6 \pm 12.0$ & 3.99 & $<0.0001$ \\
\hline \multicolumn{6}{|l|}{ Blood pressure } \\
\hline Systolic (mmHg) & $128.0 \pm 19.9$ & $118.0 \pm 19.4$ & $123.5 \pm 20.3$ & 3.54 & 0.001 \\
\hline Diastolic (mmHg) & $82.8 \pm 12.0$ & $77.1 \pm 11.6$ & $80.2 \pm 12.1$ & 3.32 & 0.001 \\
\hline \multicolumn{6}{|l|}{ Urinary excretion } \\
\hline Volume (ml/d) & $1509 \pm 571$ & $1370 \pm 578$ & $1442 \pm 577$ & 1.68 & 0.094 \\
\hline Creatinine $(\mathrm{mmol} / \mathrm{d})$ & $11.0 \pm 2.3$ & $7.6 \pm 1.6$ & $9.4 \pm 2.6$ & 11.34 & $<0.0001$ \\
\hline Sodium (mmol/d) & $218.3 \pm 81.4$ & $183.8 \pm 69.8$ & $201.5 \pm 77.7$ & 3.14 & 0.002 \\
\hline Potassium (mmol/d) & $45.9 \pm 17.9$ & $47.7 \pm 27.7$ & $46.8 \pm 23.2$ & -0.53 & 0.594 \\
\hline Sodium-to-potassium ratio & $5.2 \pm 2.2$ & $4.6 \pm 2.2$ & $4.9 \pm 2.2$ & 1.97 & 0.05 \\
\hline Salt intake $(\mathrm{g} / \mathrm{d})$ & $12.8 \pm 4.8$ & $10.8 \pm 4.1$ & $11.8 \pm 4.5$ & 3.14 & 0.002 \\
\hline
\end{tabular}

indicating an Acceptable 24-hour urine collection [18]. Daily salt intake was estimated based on calculation of 24-hour urinary sodium excretion on the assumption that all sodium ingested was in the form of sodium chloride.

\section{Statistical analysis}

All statistical analyses were performed using SAS software 9.3 (SAS Inc., Cary, North Carolina, USA). Twosided $P<0.05$ was considered statistically significant. Results were expressed as mean \pm SD or median and 25th-75th percentiles. Sample characteristics were compared between sexes using a Student's $t$-test. After salt intake from weighted condiments records was transformed using log, Pearson's linear correlation was used to detect bivariate associations. Standard linear regression was used to assess associations between sodium and BP, with body mass index (BMI), sex, and age used as covariates.

\section{Results}

\section{Characteristics of study participants}

Demographic data on the participants are given in Table 1. Average urine volume was 1442 (SD 577) mL/d. Average urine creatinine excretion was 9.4 (SD 2.6) $\mathrm{mmol} / \mathrm{d}$. Urine creatinine excretion was significantly higher in men (11.0 \pm $2.3 \mathrm{mmol} / \mathrm{d})$ than in women $(7.6 \pm 1.6 \mathrm{mmol} / \mathrm{d})$. Mean potassium excretion was 46.8 (SD 23.2) $\mathrm{mmol} / \mathrm{d}$, corresponding with a dietary potassium intake of 1.8 (SD 0.9) g/d in the whole group. The mean sodium:potassium ratio was 4.9 in the whole group and 5.2 and 4.6 in males and females, respectively.

\section{Sodium and salt intake in adults}

Urinary sodium excretion in the whole group was 201.5 (SD $77.7 \mathrm{mmol} / \mathrm{d}$ ), which corresponds to 11.8 (SD 4.5) g/d $\mathrm{NaCl}$. Urinary sodium excretion was significantly higher in men $(218.3 \pm 81.4 \mathrm{mmol} / \mathrm{d})$ than in women $(183.8 \pm$ $69.8 \mathrm{mmol} / \mathrm{d} ; p=0.002$, Figure 1$)$, corresponding to 12.8 (SD 4.8) g/d and 10.8 (SD 4.1) g/d NaCl, respectively. Overall, $92.1 \%$ of the participants $(96.9 \%$ of men and $87.1 \%$ of women) had intakes of over $6 \mathrm{~g}$ salt $(\mathrm{NaCl}) / \mathrm{d}(102 \mathrm{mmol}$ of $\mathrm{Na} / \mathrm{d})$ (recommended Chinese maximum ).

\section{Salt intake from weighed condiments records}

For the whole population, the median salt intake from weighed condiment records was $10.1 \mathrm{~g} / \mathrm{d}$. The main

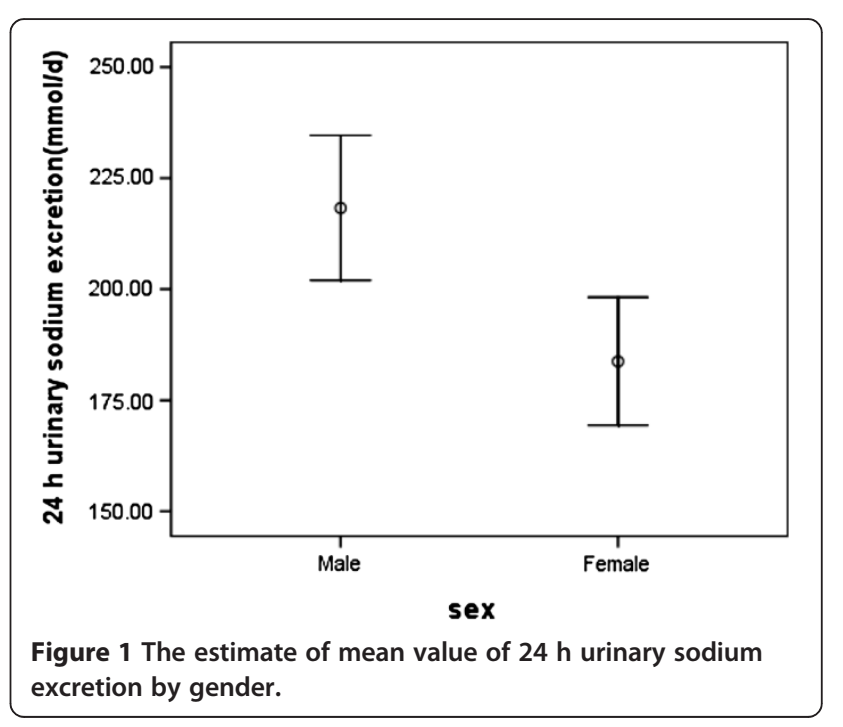


Table 2 Correlation between salt intake from condiments and salt excretion

\begin{tabular}{lccccc}
\hline Condiments usage (g/d) & Median & 25th-75th percentiles & \% & Correlation coefficients & P value \\
\hline Salt & 7.3 & $5.7-11.3$ & 74.7 & 0.19 & 0.017 \\
Soysauce & 1.4 & $0.6-2.4$ & 15.0 & 0.065 & 0.389 \\
Jam & 0.2 & $0-0.7$ & 4.7 & 0.129 & 0.202 \\
Monosodium & 0.4 & $0.2-0.9$ & 5.2 & 0.322 & 0.001 \\
Vinegar & 0.03 & $0-0.07$ & 0.4 & 0.154 & 0.03 \\
$\quad$ Total & 10.1 & $7.6-15.6$ & 100 & 0.20 & 0.005 \\
\hline
\end{tabular}

source of salt was from home cooking salt (74.7\%), followed by soy sauce (15.0\%), and other condiments (10.3\%). Salt intake from weighed condiments was $10.1 \mathrm{~g} / \mathrm{d}$ compared with 11.8 (SD4.5) g/d from urinary $\mathrm{Na}$ excretion $(p=0.575)$. Salt intake from condiments and salt excretion were weakly correlated $(r=0.20$, $p=0.005$ ) (Table 2).

\section{Urinary sodium and blood pressure}

Systolic BP $(\mathrm{r}=0.25, p=0.0006)$ and diastolic BP $(\mathrm{r}=0.22$, $p=0.0020)$ were positively and significantly correlated with 24-hour urinary $\mathrm{Na}$ excretion. Adjusting for sex, age, and BMI, linear regression analyses found that sodium excretion was positively associated with systolic BP in all adjusted models. After adjusting for sex, age, and BMI, no significant association between urinary sodium and diastolic BP was found (Table 3).

\section{Discussion}

We found the average urinary sodium excretion among adults in Yantai was 201.5 (SD 77.7) mmol/d (11.8 g salt/d).This level is double the recommended intake of $5 \mathrm{~g}$ salt/d issued by the WHO in 2012[19] and the China Nutrition Recommendations[20]. Thus, salt intake among Yantai adults is very high.

For China, only limited data on sodium intake assessed using 24-hour urine collection is available. Liu et al.

Table 3 Relationship between blood pressure and urinary sodium

\begin{tabular}{lcccc}
\hline Variable & $\boldsymbol{\beta}$ & SE & Standardized $\boldsymbol{\beta}$ & P Value \\
\hline Systolic blood pressure & & & & \\
Unadjusted & 0.06441 & 0.01835 & 0.24740 & 0.0006 \\
Model 1* & 0.05091 & 0.01668 & 0.19553 & 0.0026 \\
Model 2* & 0.04012 & 0.01617 & 0.15794 & 0.0118 \\
Diastolic blood pressure & & & & \\
Unadjusted & 0.03460 & 0.01102 & 0.22277 & 0.0020 \\
Model 1* & 0.02724 & 0.01071 & 0.17536 & 0.0118 \\
Model 2* & 0.01925 & 0.01008 & 0.12394 & 0.0576 \\
\hline
\end{tabular}

*Model 1: adjusted for age and sex; Model2: adjusted for age, sex and body mass index. reported urinary sodium excretion was 188.4 (SD 86.0) $\mathrm{mmol} / \mathrm{d}$ in a population of 48-56-year-olds in China [21]. Most studies find the intake and excretion of $\mathrm{Na}$ higher among men, compared to women, perhaps because of their overall higher food intake and differences in dietary habits $[10,16,22]$.

In China, salt intake is high mainly because of the tradition of adding excessive salt to foods (both during cooking and at the table) and the high consumption of soy sauce $[10,23,24]$. A recent study suggested that most dietary sodium (76\%) in China was from salt added in home cooking [25]. The results of the present study also show that the main source of salt was from home cooking salt (74.7\%) and soy sauce (15.0\%). A weak correlation between salt intake from condiments and salt excretion was obtained. By comparison, most of the salt in western countries, in fact $75-80 \%$, is derived from processed foods [10].

Linear regression models clearly demonstrated a positive linear association between urinary sodium and systolic BP in this study. Accordingly, we found a reduction in sodium intake of $100 \mathrm{mmol} / \mathrm{d}$ (6 g salt/day) was associated with a $4.0 \mathrm{mmHg}$ reduction in systolic BP. Our findings provide supporting evidence that the current high intake of sodium is related to higher BP among the population. This finding is consistent with the Intersalt international cross-population study [26] and the SALTURK study [27], which estimated that a $100 \mathrm{mmol} /$ day lower sodium intake was associated with $2.2 \mathrm{mmHg}$ and $5.8 \mathrm{mmHg}$ lower systolic BP, respectively. An Australian study found that a reduction in sodium intake of $100 \mathrm{mmol} / \mathrm{d}$ was associated with a $2.3 \mathrm{mmHg}$ reduction in systolic BP [28]. Importantly, a population-wide fall in systolic BP of $2 \mathrm{mmHg}$ has been predicted to lower stroke mortality by $10 \%$ and ischemic heart disease and other vascular diseases by $7 \%$ [29].

A major strength of our study is that we used the 'gold standard' 24-hour urine collection to estimate sodium intake. Completeness of the urine sample was ascertained through urinary creatinine excretion. However, our study has some limitations, including a small sample size because of the pilot nature of the study, which limits the precision to estimate the effect 
strength of salt intake on BP and Additionally, a single measure was not able to assess the impact that day-today variability of sodium intake will have on urinary sodium excretion. For assessment sources of salt intake, this study only deals with added salt during home cooking and not with salt in the total diet. For the linear regression analyses, some potential confounding factors such as physical activity, total energy intake, alcohol consumption, and family history of hypertension, have not been adjusted.

\section{Conclusions}

The present results show that dietary salt intake in Yantai adults was high. Higher salt intake was associated with higher systolic BP. Effective reduction of salt consumption requires specific targeting of those condiments in home cooking that contribute most to salt intake, including cooking salt and soy sauce.

\section{Competing interests}

The authors declare that they have no competing interest.

\section{Authors' contributions}

MW, JM and GM conceived and designed the study. MW, YC, BZ, JL, WL, FN and $\mathrm{HL}$ performed the experiments. JX and MW conducted the data analyses and drafted the manuscript. All authors read and approved the final manuscript.

\section{Acknowledgments}

The authors would like to thank all investigators from provincial and country level CDC and all participants of the survey. The authors thank Dr. Michael Engelgau for his comments and suggestions.

\section{Author details}

${ }^{1}$ National Institute For Nutrition and Food Safety, Chinese Center for Disease Control and Prevention, 100050 Beijing, China. ${ }^{2}$ Yantai Center for Disease Control and Prevention, 264003 Yantai, China. ${ }^{3}$ Yantai Fushan District Center for Disease Control and Prevention, 265500 Yantai, China. ${ }^{4}$ Yantai Penglai County Center for Disease Control and Prevention, 265600 Yantai, China. ${ }^{5}$ National Center for Chronic and Noncommunicable Disease Control and Prevention, Chinese Center for Disease Control and Prevention, 100050 Beijing, China.

Received: 29 August 2013 Accepted: 4 February 2014

Published: 8 February 2014

\section{References}

1. Stamler J: The INTERSALT study: background, methods, findings, and implications. Am J Clin Nutr 1997, 65(Suppl 2):626S-642S.

2. Sacks FM, Svetkey LP, Vollmer WM, Appel LJ, Bray GA, Harsha D, Obarzanek E, Conlin PR, Miller ER 3rd, Simons-Morton DG, Karanja N, Lin $\mathrm{PH}$ : Effects on blood pressure of reduced dietary sodium and the dietary approaches to stop hypertension (DASH) diet. New Engl J Med 2001, 344(1):3-10

3. He FJ, Li J, Macgregor GA: Effect of modest salt reduction on blood pressure: a meta-analysis of randomized studies. J Hum Hypertens 2002, 16(11):761-770.

4. Cook NR, Cutler JA, Obarzanek E, Buring JE, Rexrode KM, Kumanyika SK, Appel LJ, Whelton PK: Long term effects of dietary sodium reduction on cardiovascular disease outcomes: observational follow-up of the trials of hypertension prevention (TOHP). BMJ 2007, 334(7599):885-888.

5. Bibbins-Domingo K, Chertow GM, Coxson PG, Moran A, Lightwood JM, Goldman L: Projected effect of dietary salt reductions on future cardiovascular disease. N Engl J Med 2010, 362(7):590-599.
6. Beaglehole R, Bonita R, Horton R, Adams C, Alleyne G: Priority actions for the non-communicable disease crisis. Lancet 2011, 377(9775):1438-1447

7. Ministry of Health: Annual Report on Health Statistics. Beijing: Peking Union Medical College Publishing House; 2010.

8. China CDC, China News: Salt reduction and hypertension prevention. Beijing: China News Publishing House; 2011.

9. Bureau of Disease Control and Prevention, $\mathrm{MOH}$ and China CDC: China NCD Report 2011. Beijing, China: $\mathrm{MOH} ; 2011$.

10. Ortega RM, Lopez-Sobaler AM, Ballesteros JM, Perez-Farinos N, RodriguezRodriguez E, Aparicio A, Perea JM, Andres P: Estimation of salt intake by $24 \mathrm{~h}$ urinary sodium excretion in a representative sample of Spanish adults. Br J Nutr 2011, 105(5):787-794.

11. INTERSALT Cooperative Research Group: INTERSALT study. An international co-operative study on the relation of blood pressure to electrolyte excretion in populations. I.Design and methods. $J$ Hypertens 1986, 4(6):781-787.

12. Elliott P, Stamler R: Manual of operations for 'INTERSALT', an international cooperative study on the relation of sodium and potassium to blood pressure. Control Clin Trials 1988, 9(Suppl 2):1S-117S.

13. Pietinen $\mathrm{P}$, Valsta LM, Hirvonen $\mathrm{T}$, Sinkko $\mathrm{H}$ : Labeling the salt content in foods: a useful tool in reducing sodium intake in Finland. Public Health Nutr 2008, 11(4):335-340.

14. Ribic CH, Zakotnik JM, Vertnik L, Vegnuti M, Cappuccio FP: Salt intake of the Slovene population assessed by $24 \mathrm{~h}$ urinary sodium excretion. Public Health Nutr 2010, 13(11):1803-1809.

15. World Health Organization: Reducing Salt Intake in Populations: Report of a WHO Forum and Technical Meeting, 5-7 October 2006, Paris, France. Geneva: WHO; 2007

16. Brown IJ, Tzoulaki I, Candeias V, Elliott P: Salt intakes around the world: implications for public health. Int J Epidemio/ 2009, 38(3):791-813.

17. Institution of nutrition and food safety, China CDC: China food composition (2004, second edition). Beijing: Peking University Health Science Center Publishing House; 2004.

18. Liu L, Ikeda K, Yamori Y: Inverse relationship between urinary markers of animal protein intake and blood pressure in Chinese: results from the WHO cardiovascular diseases and alimentary comparison (CARDIAC) study. Int J Epidemio/ 2002, 31(1):227-33.

19. World Health Organization: Guideline: Sodium intake for adults and children. Geneva: WHO; 2012

20. Chinese Nutrition Society: The Dietary Guidelines for Chinese Residents. Lasa: Tibetan People's Publishing House; 2008.

21. Liu L, Ikeda K, Yamori Y: Twenty-four hour urinary sodium and 3-methyihistidine excretion in relation to blood pressure in Chinese: results from the china-Japan cooperative research for the WHO-CARDIAC study. Hypertens Res 2000, 23(2):152-157.

22. Laatikainen $T$, Pietinen $P$, Valsta $L$, Sundvall J, Reinivuo $H$, Tuomilehto J: Sodium in the Finnish diet: 20-year trends in urinary sodium excretion among the adult population. Eur J Clin Nutr 2006, 60(8):965-970.

23. Zhou BF, Stamler J, Dennis B, Moag-Stahlberg A, Okuda N, Robertson C, Zhao L, Chan Q, Elliott P: INTERMAP research group nutrient intakes of middle-aged men and women in china, Japan, United Kingdom, and United States in the late 1990s: the INTERMAP study. J Hum Hypertens 2003, 17(9):623-630.

24. Liu L, Liu L, Ding $Y$, Huang Z, He B, Sun S, Zhao G, Zhang H, Miki T, Mizushima S, Ikeda K, Nara Y, Yamori Y: Ethnic and environmental differences in various markers of dietary intake and blood pressure among Chinese Han and three other minority peoples of china: results from the WHO cardiovascular diseases and alimentary comparison (CARDIAC) study. Hypertens Res 2001, 24(3):315-322.

25. Anderson CA, Appel LJ, Okuda N, Brown IJ, Chan Q, Zhao L, Ueshima H, Kesteloot H, Miura K, Curb JD, Yoshita K, Elliott P, Yamamoto ME, Stamler J: Dietary source of sodium in China, Japan, the United Kingdom, the United States, women and men aged 40 to 59 years: the INTERMAP study. J Am Diet Assoc 2010, 110(5):736-745.

26. Intersalt Cooperative Research Group: Intersalt: an international study of electrolyte excretion and blood pressure. results for 24 hour urinary sodium and potassium excretion. BMJ 1988 297(6644):319-328

27. Erdem Y, Arici M, Altun B, Turgan C, Sindel S, Erbay B, Derici U, Karatan O, Hasanoglu E, Caglar S: The relationship between hypertension and salt 
intake in Turkish population: SALTURK study. Blood Press 2010,

19(5):313-318.

28. Huggins CE, O'Reilly S, Brinkman M, Hodge A, Giles GG, English DR, Nowson

CA: Relationship of urinary sodium and sodium-to-potassium ratio to blood pressure in order adults in Australia. Med J Aust 2011, 195(3):128-132.

29. Lewington S, Clarke R, Peto R, Collins R: Prospective studies collaboration. Age-specific relevance of usual blood pressure to vascular mortality: a meta-analysis of individual data for one million adults in 61 prospective studies. Lancet 2002, 360(9349):1903-1913.

doi:10.1186/1471-2458-14-136

Cite this article as: Xu et al.: Estimation of salt intake by 24-hour urinary sodium excretion: a cross-sectional study in Yantai, China. BMC Public Health 2014 14:136.

\section{Submit your next manuscript to BioMed Central and take full advantage of:}

- Convenient online submission

- Thorough peer review

- No space constraints or color figure charges

- Immediate publication on acceptance

- Inclusion in PubMed, CAS, Scopus and Google Scholar

- Research which is freely available for redistribution 